\title{
A ESPORTIVIZAÇÃO DA CAPOEIRA: REFLEXÕES TEÓRICAS INTRODUTÓRIAS
}

Leonardo Prata Alves

Paulo César Montagner

\section{Resumo}

Este estudo é resultado de uma pesquisa bibliográfica, somadas às minhas reflexões frente ao tema da esportivização da Capoeira. Mostra-se, historicamente, os caminhos da Capoeira, desde a origem ao fenômeno de esportivização, bem como, os diferentes argumentos contrários e favoráveis a este fenômeno.

\section{Palavras-Chaves}

Capoeira; Esportivização; Regional; Angola; JEBs

\section{THE SPORTIVIZATION OF THE CAPOEIRA: INTRODUCTORY THEORETICAL REFLECTIONS}

Leonardo Prata Alves

Orientador: Paulo César Montagner

\begin{abstract}
This study is a result of a bibliography research added to my reflections about the sportivization of Capoeira theme. Shows, historically, the ways of Capoeira, since of the beginning until the sportivization phenomenon, as well as the different opposing and favorable arguments to this phenomenon.
\end{abstract}

\section{Key-Words}

Capoeira; Sportivization; Regional; Angola; JEBs 


\section{INTRODUÇÃO}

Este estudo traz as discussões que permeiam o tema "Esportivização da Capoeira", mostrando, através de uma revisão bibliográfica, de depoimentos extraídos de vídeo e das minhas reflexões, os pontos discordantes e favoráveis a esse processo. Percebe-se, na literatura, um apontamento crítico negativo frente à esportivização da Capoeira.

Trago críticas positivas, em relação à mesma, dando margem a futuras discordâncias sobre os meus argumentos.

\section{A ESPORTIVIZAÇÃO DA CAPOEIRA}

A semente da esportivização da Capoeira foi lançada com a criação da Capoeira Regional Baiana (1930), de Manuel dos Reis Machado - o Mestre Bimba. É neste momento que aparecem modificações consideráveis nos valores da Capoeira tradicional, ou Capoeira de Angola, como era conhecida. Bimba, normatiza a Capoeira, trazendo uma recodificação que se antagoniza a alguns elementos essenciais, como a ludicidade, a espontaneidade e a indiscriminação de seus participantes. Porém, é a partir de $1^{\circ}$ de janeiro de 1973, com a vinculação da Capoeira à Confederação Brasileira de Pugilismo (CBP), que se intensifica o fenômeno da esportivização.

Ao ser esportivizada, a Capoeira passa a ser tratada de forma unidimensional e fragmentada, pois aspectos importantes são deixados de lado, como à historicidade, a ludicidade e a subjetividade, frente a outros que são o tecnicismo e o condicionamento físico.

Esta necessidade de regulamentação da Capoeira, transformando-a em esporte, é fruto de um quadro de desenvolvimento industrial, de uma urbanização e da hegemonia que o esporte moderno passa a exercer sobre os demais elementos da "cultura do movimento".

Na década de 60, muitos alunos do Mestre Bimba emigraram pra São Paulo e Rio de Janeiro, atraídos pelas possibilidades econômicas. Com isso, contribuíram muito para a difusão da Capoeira Regional Baiana e, conseqüentemente, para a idéia de uniformização da Capoeira.

Ao novo regime de governo (ditadura), frente às manifestações sociais que se opunha a todo instante, cabia substituir e divulgar uma nova concepção de cultura que pudesse atuar como analgésico destes movimentos sociais. $\mathrm{O}$ esporte, então, aparece como a prática mais adequada para alcançar tais objetivos. 
Em fins da década de 60, surgem os primeiros campeonatos e tentativas de regulamentação da Capoeira. Acontecem, em 1968 e 1969, o primeiro e o segundo simpósios brasileiros de Capoeira, respectivamente, numa base da Força Aérea, no Rio de Janeiro. Nestes eventos, tentou-se padronizar os nomes dos golpes, sistema de graduação de alunos e critérios para graduação de Mestres, tudo com o intuito de fundar as federações de Capoeira e dar a mesma o caráter de "esporte nacional". É neste mesmo período que ocorrem, na Bahia, os primeiros campeonatos de Capoeira. A inclusão da Capoeira nos Jogos Escolares Brasileiros (JEBs), em 1985, contribuiu para o processo de esportivização, pois passa a fazer parte da mais representativa festa dos esportes estudantis no Brasil.

Os JEBs também contribuíram em relação ao modelo a ser estabelecido nas competições de Capoeira. As primeiras versões dos JEBs não diferiam muito do que vinha ocorrendo em termos de campeonatos de Capoeira. Valorizavam somente a eficiência dos golpes e defesas, deixando de lado muitos outros elementos que dão pluralidade à Capoeira. Eram campeonatos inspirados nos modelos de outras artes marciais, que acabaram desprestigiando a Capoeira devido à violência que ocorria. Porém, graças ao empenho das pessoas envolvidas com a modalidade Capoeira, nos JEBs, o modelo de campeonato foi sendo alterado, ano após ano, visando avaliar outros aspectos como o conhecimento histórico, criatividade, oralidade, pesquisa, musicalidade, organização, etc.

As entidades competentes trabalhavam, no sentido de proporcionar uma versão de Capoeira não fragmentada, tentando abranger o seu total significado, porém havia aqueles que criticavam esses esforços, devido ao jogo político-ideológico.

A Capoeira sempre foi polêmica e dialética! Continuam existindo os que a defendem e até os que atacam-na. Quando fui Presidente do Conselho Nacional de Desportos (CND), tive a oportunidade histórica e intelectual de participar deste debate. Inicialmente dei apoio ao movimento daqueles que defendiam a Capoeira como manifestação cultural, e não aceitavam que ela virasse esporte. Mais tarde, em 1989, quando acumulei com o CND a Secretaria Nacional de Educação Física/desportos, compreendi, influenciado e estimulado pelos professores Sérgio Graça e César Barbieri, que a Capoeira apresentava-se num "sincretismo" cultural muito grande, podendo ser aceita em várias perspectivas e expectativas. Foi nesse sentido, que conseguimos, os três juntos, reunir em Ouro Preto (Minas Gerais), na I Jornada Cultural de Capoeira, todos os movimentos e percepções de Capoeira do país. Foi um dos instantâneos mais emocionantes da minha vida intelectual, quando naquele memorável dia 18 de Dezembro de 1987, ao chegar em Ouro Preto, num dia de condições climáticas adversas, me deparei com 
centenas de capoeiristas brasileiros, de todas as "facções" opostas, jogando na praça principal daquela cidade histórica, debaixo de chuva intensa. Foi indescritível! (TUBINO, 1995, p. 13).

\section{CRÍTICAS CONTRÁRIAS À ESPORTIVIZAÇÃO DA CAPOEIRA - PERDA DA ESSÊNCIA:}

Há o temor de que os capoeirístas, ou a Capoeira, diferentemente de sua origem e sua história de resistência - resistência à escravidão, à proibição de sua prática, à marginalização dos negros libertos, ao fim da Capoeira Tradicional (Angola), etc -passe a seguir às regras impostas por órgãos administrativos e pseudo-representativos -uma vez que nem todos os capoeirístas aceitam a representatividade das federações e Confederação - e acate a todas as decisões e tendências de caminhos a serem trilhados pela Capoeira, traçados muitas vezes, por interesses de pequenos grupos, que não correspondem ao interesse do grande coletivo de interessados.

\section{- TENDÊNCIA AO ALTO RENDIMENTO (EXCLUSÃO DOS MAIS FRACOS):}

O esporte moderno pode ser realizado e, portanto, dividido em diferentes níveis: esporte-educação, esporte-participação e esporte-rendimento.

O esporte de rendimento acaba influenciando aos outros dois modelos, pois é nele, que encontra-se toda uma estrutura de espetacularização, ocasionada pela forte presença da mídia e pela presença do marketing esportivo. É no esporte de rendimento que há a possibilidade de ascensão econômico-social significativa, através do acúmulo de capitais e de títulos, que acabam fornecendo a mudança de status (classes sociais). Observamos, atualmente, crianças sendo pedagogizadas, dentro do esporte, de uma maneira totalmente tecnicista, precocemente, visando à construção de um futuro campeão. Observamse discussões agressivas ("bate-boca"), dentro da prática de um esporte de participação (lazer), onde, teoricamente, os participantes deveriam buscar o entretenimento, a integração, etc. Exemplo: o futebol dos finais de semana. Possivelmente, tais manifestações agressivas, sejam fruto da influência do esporte de rendimento, onde a lógica do ganhar ou perder é o que predomina. Diariamente, o participante do esporte-participação já vive, em seu cotidiano, rodeado de cobranças, metas e prazos e, em um momento no qual deveria relaxar, estressa-se, pois não consegue desvencilhar-se do pensamento capitalista que se encontra incutido no esporte.

Este é um dos pontos criticados pelos capoeiristas que são contra a "Esportivização da Capoeira". Eles temem pela extinção da liberdade propiciada pelo jogo da Capoeira. Temem pelo fím da malícia, da arte 
de ludibriar, pelo fim do improviso, pelo fim do sorriso no rosto, visto que, pela lógica do esporte moderno, os objetivos são o que importa e, no caso do esporte-rendimento, o maior desses objetivos é a vitória.

\section{SUPERVALORIZAÇÃO DO TECNICISMO E DAS CAPACIDADES BIOMOTORAS:}

Na busca da excelência e na intenção da superação sobre os outros capoeiristas, para ser "o melhor", "o campeão", os movimentos corporais da Capoeira tomam grau de importância maior frente a outros conteúdos dessa tão complexa arte-luta, acabando por supervalorizar a prática de golpes, esquivas, floreios e condicionamento físico, nas estruturas das aulas. Os conteúdos referentes à musicalidade, à história e à ludicidade, por exemplo, acabam tendo um espaço muito menor de dedicação.

...foram acrescentados pontapés e golpes de mão que, tradicionalmente, não existiam na Capoeira, modificou-se a execução de certos golpes que já existiam, tornando-os "mais técnicos" (portanto mais parecidos com os do karatê), introduziram-se técnicas de "defesa pessoal" e, às vezes, até são utilizadas "guardas" com nítida influência oriental durante os jogos e práticas. (FRIGÉRIO, 1989, p. 91).

\section{FALÊNCIA (FINANCEIRA) DE GRUPOS E ESTILOS QUE NÃO SIGAM A LINHA DA CAPOEIRA ESPORTE:}

Os grupos de Capoeira mais organizados e estruturados, pela lógica de mercado, trabalham para ampliar o seu mercado-consumidor, oferecendo o "produto Capoeira" por um melhor custo-benefício. Usam-se de estratégias de marketing para monopolizar o mercado-consumidor, o que fatalmente implica na derrocada de outros grupos, mestres e professores que têm a Capoeira como a sua principal fonte de renda.

\section{- TORNA-SE SELETIVA, VISTO QUE TRABALHA COM A LÓgICA DO "VENCEDOR E PERDEDOR":}

A lógica da superação e da sobrepujança sobre o outro, característica marcante do esporte-rendimento, leva a uma busca pela melhoria continua, tendo como objetivo tornar-se o melhor capoeirista do seu grupo, cidade, Estado, etc. Pessoas menos preparadas fisicamente e psicologicamente, para entrar neste tipo de "disputa" podem, encontradas neste contexto, desanimar da prática da Capoeira. Essencialmente, a Capoeira tem uma imagem de arte, dança, brincadeira e luta. As pessoas, muitas vezes, não procuram a Capoeira somente por sua eficiência marcial e sim, procuram-na para melhorar a saúde, pela musicalidade, pela sociabilidade. Na lógica do rendimento, a Capoeira torna-se, para os não 
capoeiristas-atletas, um outro fator de estresse, pois configura-se cheia de exigências quanto à melhoria da performance.

\section{RISCO DE QUEBRA DA SUPREMACIA BRASILEIRA FRENTE A MAIOR CIENTIFICIDADE, NAS METODOLOGIAS DO TREINAMENTO ESPORTIVO, DE OUTROS PAÍSES:}

No esporte-rendimento, os resultados são reflexos do planejamento, empenho e dedicação aos treinamentos. Assim, países como os Estados Unidos, Cuba, China, Rússia, Inglaterra, Alemanha e Canadá, por exemplo, que têm as Ciências dos Esportes bem desenvolvidas, comparadas ao Brasil, poderão, um dia, superar-nos (brasileiros) na modalidade Capoeira. Tais países disputam, entre si, a hegemonia esportiva, como reflexo da hegemonia sócio-econômica. Na Guerra Fria (1945 - 1949), os Estados Unidos e a ex-URSS (União das Repúblicas Socialistas Soviéticas) disputavam a superioridade nos esportes com o intuito de refletir a sua grande força hegemônica perante o resto do mundo.

Com a uniformização do jogo de Capoeira, cria-se a possibilidade do comparativo e, portanto, a possibilidade de superação e inferiorização. Surge a possibilidade que a Capoeira passe a ser sinônimo de outro país, e não do Brasil, que consiga um desempenho melhor, em eventos/campeonatos internacionais.

\section{CRÍTICAS FAVORÁVEIS À ESPORTIVIZAÇÃO DA CAPOEIRA}

Os argumentos encontrados, no sentido de reforçar a existência da Capoeira-Esporte, são escassos. Quando o aparecem, reforçam os benefícios da existência do modelo de Capoeira voltada para a educação e para o lazer. A Capoeira voltada para o alto-rendimento é extremamente criticada negativamente, pois sempre mentaliza-se um modelo fragmentado, que supervaloriza as técnicas corporais, em detrimento dos outros conteúdos da capoeira (musicalidade, criatividade, conhecimento histórico, etc). Hoje, o modelo de competição usado pela FICA, Federação Internacional de Capoeira, e conseqüentemente pela $\mathrm{CBC}$, Confederação Brasileira de Capoeira, fragmentam o evento em categorias: competições de Capoeira Regional, de Capoeira Angola, de conjuntos, de Ladainhas, de Duplas, Ginástico-acrobáticas, contemporâneas, concurso de trabalhos teóricos e concurso de cantigas inéditas. O capoeirista participante inscreve-se somente naquela ou naquelas categorias que desejar ou que lhe convier. Este modelo pode levar a uma formação parcial, visto que, para ser campeão de uma das categorias, o capoeirista dedica-se muito mais a uma categoria frente às outras. Porém, se o capoeirista for um membro credenciado à federação de seu Estado e esta, for vinculada à CBC, a 
parcialidade na formação dificilmente ocorrerá, pois a FICA, criou regras das quais a CBC se orienta, das quais, cursos específicos e indicações de leituras, são contemplados, objetivando uma formação plena e de qualidade do capoeirista. É a sistematização e a burocratização da Capoeira. Uma manifestação sócio-cultural que anteriormente fora livre de limites e imposições e migra, na visão de muitos, para um processo de "engessamento", seguindo as diretrizes de órgãos reguladores.

$\mathrm{Na}$ linha do esporte-participação, praticado nas escolas e nos ambientes de lazer, os benefícios propiciados pela Capoeira são os mesmos de outras modalidades esportivas, salientando o aspecto desta ser oriunda no Brasil e propiciar o resgate da história do povo brasileiro e de sua nação, bem como as discussões que permeiam o tema, a exemplo da "Esportivização" da Capoeira.

São colocadas, neste trabalho, algumas concepções teórico-subjetivas, sobre alguns aspectos positivos da Capoeira, no universo do esporte de rendimento. Tais concepções são:

\section{- DIFUSÃO DA CAPOEIRA ATRAVÉS DE EVENTOS, CAMPEONATOS:}

Eventos esportivos costumam mobilizar um grande público de expectadores. Assim, os campeonatos e outros eventos de Capoeira contribuem para a propaganda desta arte-luta brasileira.

\section{- ATENDE A OUTROS SEGMENTOS DE MERCADO (PÚBLICO QUE VISA ESTÉTICA; A EFICIÊNCIA MARCIAL):}

Com o grande preparo físico que o capoeirista apresenta na atualidade, fruto da grande exigência de treinamento em busca de ser o "melhor", o corpo do capoeirista modificou-se, na história. Antes, o capoeirista era aquele sujeito magro, franzino e baixo e hoje, são capoeiristas-atletas, com um corpo muito robusto, fruto dos esteróides anabolizantes e do treinamento com pesos. Isto desperta nas pessoas, que não praticam Capoeira, porém buscam um "corpo malhado", a prática da mesma. Alguns buscarão na Capoeira não a sua complexidade de gestos, ritos, história e musicalidade, mas sim, um corpo trabalhado e bonito, propiciado pela exigência de seu treinamento.

\section{INTERNACIONALIZAÇÃO DA CAPOEIRA:}

A maioria dos grupos de Capoeira, que tem representatividade fora do Brasil, apresentam o estilo de jogo da Capoeira Regional e da Capoeira Contemporânea. Comparado a estes, a expressividade da Capoeira Angola, fora do país, é pouca. Tanto a Capoeira Regional e a Contemporânea apresentam-se esportivizadas, o que aponta ser, a Capoeira Esporte, muito mais vendável que a Capoeira Angola. 


\section{CIENTIFICIDADE}

Visto que, a Capoeira esportivizada traz consigo a lógica da sobrepujança, as teorias do treinamento esportivo entram, dando amparo a melhora da performance dos atletas, de forma muito objetiva. Muitas metodologias de treinamento aplicadas anteriormente, fruto da herança de antigos "mestres" e professores, acabam sendo confrontadas perante o embasamento técnico-científico.

O acréscimo das ciências não se restringe aos aspectos técnico-fisiológicos, mas também, às descobertas históricas, às discussões provindas de outras áreas como a Antropologia, Sociologia e Psicologia, que têm, na Capoeira, assuntos de interesse de suas pesquisas.

\section{GANHO DE VISIBILIDADE}

A Capoeira, após a sua transição de atividade de "negros vadios" para o status de esporte, passa a ser freqüentemente utilizada em comerciais televisivos, circos, telenovelas, filmes e vinhetas. Filmes recentes, como Madame Satã (2002), Esporte Sangrento (1993), Desafio Mortal (1996), entre outros, mostraram a Capoeira, dando ênfase nos seus golpes mais ágeis e difíceis, que acabam por retratar a Capoeira esportivizada.

No espetáculo La Nouba, do Cirque du Soleil, movimentos de Capoeira são apresentados como manifestação de arte, beleza e domínio corporal, por um de seus atores.

Recentemente, em uma retransmissão da novela Sinhá Moça (2006), veiculada pela Rede Globo de Televisões, também mostrou a Capoeira.

\section{-SUPREMACIA BRASILEIRA:}

A Capoeira, por ser de origem brasileira, e nós, brasileiros e capoeiristas, termos a vantagem dos longos anos de prática da mesma, frente a outros países que a estão conhecendo agora ou tomaram contato com a mesma à poucos anos, acabamos por ter uma certa "supremacia" quanto a desenvoltura, compreensão e performance na prática da mesma. Além disso, temos toda uma identidade com seus cânticos e com sua história.

\section{IDENTIDADE NACIONAL}

A Capoeira adquire o título de "Esporte Nacional". Um método de ginástica, genuinamente brasileiro, com movimentos e expressividade próprios. A Capoeira é valorizada, assumindo a identidade de "Método de Ginástica Brasileiro", preconizando o bem-estar e melhoria da saúde de seus praticantes. 
-DETERMINA OS LIMITES DE FORMA CLARA (REGRAS), ACABANDO COMO PROBLEMA DE SOCOS E LUTA AGARRADA QUE VEM SE ESTABELECENDO:

A Capoeira, praticada em ambientes informais - rodas de rua e batizados, muitas vezes, apresenta-se de maneira violenta. Como herança de sua origem e história, a Capoeira, com exceção de alguns eventos e campeonatos, não tem suas regras bem definidas, o que acaba por desencadear, muitas vezes, socos, agarrões, etc.

A Capoeira esportiva, diferente desta, informal, citada no parágrafo anterior, tem suas regras bem definidas, levando em consideração a integridade física do atleta. Ela não conta somente com a ética pessoal dos indivíduos, mas, limita a violência pelas regras e pelo cumprimento destas.

\section{TORNA-SE PROFISSÃo, PERMITINDO AO CAPOEIRISTA SUSTENTAR-SE PELO ENSINO DA MESMA:}

O capoeirísta, professor, mestre ou instrutor, por muito tempo, além de ministrar aulas de Capoeira, tinha que ter um outro emprego que lhe proporcionasse a sobrevivência. Era deste emprego, e não da Capoeira, que eles conseguiam sua principal fonte de renda para moradia, vestimenta e alimentação. Hoje, o número de capoeiristas que sobrevivem da renda propiciada pela Capoeira é crescente. Isto ocorre graças ao grande aumento das publicações, workshops, encontros e seminários sobre Capoeira, que traz valores financeiros agregados. Além disso, o interesse de outros países, pela Capoeira, financeiramente, gera muita atração ao capoeirista.

\section{MARKETING ESPORTIVO}

A Capoeira, inserida no contexto do esporte de alto-rendimento, pode ser bem aproveitada pelo marketing esportivo, através da agregação de marcas e do uso dos meios de comunicações.

Há inúmeras maneiras de fazer isso: colocando marcas em produtos e vestimentas; colocando placas aos redores dos espaços dos eventos; "espetacularizando", através dos recursos de re-play, câmera-lenta, patrocinando atletas de destaque no cenário competitivo, etc. Enfim, as possibilidades são muitas e, como ocorre em outras modalidades esportivas, uns ganharão muito com isso, enquanto outros, talvez, percam o pouco que têm. 


\section{METODOLOGIA}

A pesquisa foi embasada em revisão de bibliografia existente sobre o tema; na minha vivência como praticante e estudioso da Capoeira; e através de depoimentos extraídos de fita VHS. Diante deste material, disserta-se sobre a esportivização da Capoeira, procurando contribuir de alguma forma para o desenvolvimento da compreensão e senso-crítico frente ao tema.

\section{RESULTADOS E CONCLUSÕES}

Os autores, consultados durante o estudo, que refletiram e discursaram sobre a esportivização da Capoeira, ficaram muito presos às questões da perda da "essência" e da exclusão de possíveis praticantes, que a Capoeira-Esporte pode trazer. Argumentam nesta linha, pautados apenas numa vertente do esporte, o esporte-rendimento. Eles desconsideraram a existência dos outros possíveis níveis de participação esportiva (lazer e educação) e não idealizaram possíveis benefícios, conseqüentes da esportivização da Capoeira.

A Capoeira teve e deve ter uma essência de resistência frente à minoria que queira "domesticá-la", porém, faz-se necessário pautar-se numa argumentação substanciada e, ter a mentalidade aberta para ouvir quem está do outro lado da discussão (CBC, FICA, Estado, etc).

E possível que coexistam diferentes níveis de práticas da Capoeira (participação, educação e competição), contudo, deve haver um diálogo, no sentido de definir modelos que não deturpem o significado desta arte, oriunda da cultura popular. Não podemos excluir a possibilidade das pessoas praticarem-na com o intuito competitivo e sim, lutar para que se defina um modelo de competição abrangente à totalidade dos seus conteúdos.

O modelo da Capoeira nos JEBs, por exemplo, após anos de reflexões e aperfeiçoamento, conseguiu contemplar os vários aspectos da Capoeira (musicalidade, historicidade, solidariedade, criticidade, sociabilidade, etc). E fato que a Capoeira, inserida como esporte-rendimento, no mesmo modelo das demais modalidades esportivas, cairá numa prática incompleta, espetacularizada, com uma super-valorização dos movimentos corporais, alterando a sua essência.

Assim, acho possível a coexistência de diferentes níveis de participação da Capoeira, mediante reflexões e argumentações bem pautadas, tendo sempre como objetivo principal a não descaracterização desta arte-luta frente a uma mercadorização da mesma. 


\section{REFERÊNCIAS}

AREIAS, A. das. O que é capoeira. São Paulo: Tribo, 1983.

BARBIERI, C. A. S. (Org.). A Capoeira nos JEBs. Brasília: CIDOCA, 1995.

CAMPOS, H. Capoeira na escola. Salvador: EDUFBA, 2001.

CAMPOS, H. Capoeira na universidade: uma trajetória de resistência. Salvador: SCT, EDUFBA, 2001.

CORDEIRO, I. C. de A. "Bota a mandinga $\hat{e}^{\prime \prime . . . ~ a ~ e s p o r t i v i z a c ̧ a ̃ o ~ d a ~ c a p o e i r a ~ e m ~ q u e s t a ̃ o ~(t c c) . ~}$ Campinas, 1992.

DAOLIO, J. Da cultura do corpo. Campinas, SP: Papirus, 1995.

DA MATTA, R. Carnavais, malandros e heróis: para uma sociologia do dilema brasileiro. Rio de Janeiro: Zahar, 1983.

SILVA, P. C. da C. Capoeira e Educação Física: uma história que dá jogo... pimeiros apontamentos sobre suas inter relações. Revista Brasileira de Ciências do Esporte, v. 23 n.1 set. 2001.

SOARES, C. E. L. A capoeira escrava e outras tradições rebeldes no Rio de Janeiro (1808 - 1850). Campinas: Ed. da UNICAMP, 2002.

Vídeo:

PASTINHA! uma vida pela Capoeira. Produção de Antônio Carlos Muricy. Rio de Janeiro: COPENE,1999. 1 videocassete ( $120 \mathrm{~min}$.) 
Leonardo Prata Alves

Faculdade de Educação Física -Unicamp

\section{Paulo César Montagner}

Faculdade de Educação Física - Unicamp

\section{Referência do artigo:}

\section{ABNT}

ALVES, L. P., MONTAGNER, P. C. A esportivização da capoeira: reflexões teóricas introdutórias. Conexões, v. 6, p. 510-521, 2008.

\section{APA}

Alves, L. P., \& Montagner, P. C. (2008) A esportivização da capoeira: reflexões teóricas introdutórias. Conexões, 6, 510-521.

\section{VANCOUVER}

Alves LP, Montagner PC. A esportivização da capoeira: reflexões teóricas introdutórias. Conexões, 2008; 6: $510-521$. 